\title{
Are great innovations driven by utopian ideas?
}

\author{
Bertil W. Hök \\ bertil.hok@senseair.com | Senseair AB, Flottiljgatan 49, SE-721 31 Västerås, Sweden / School of \\ Innovation, Design, and Engineering, Mälardalen University, Box 883, SE-721 23 Västerås, Sweden
}

\begin{abstract}
Case studies of well documented, great innovations were performed with focus on their underlying, basic ideas. In retrospect, these ideas may seem obvious, but at the time of conception, they were considered utopian, here defined as imaginative, unexpected, counterintuitive, or unrealistic by most people, including experts. The build-up of the utopian ideas in each of the case studies is shortly described along with a critical analysis about their roles, importance, and risk exposure in the individual cases. The ideas were ranked according to defined criteria of importance, risk, and utopian potential, and this ranking was compared to the ranking of the overall impact of the analyzed innovations. The results suggest that the utopian idea potential correlates with the overall impact. The World Wide Web and the smartphones are prominent examples of great innovations driven by utopian ideas. The significance of these findings is discussed in view of current innovation models and in recognition of the heuristic character of the reported investigation.
\end{abstract}

Keywords. Correlation; Overall impact; Utopian potential; Case studies; Great innovations; Heuristic reasoning.

Cite paper as: Hök, B., (2018). Are great innovations driven by utopian ideas?, Journal of Innovation Management, www.open-jim.org, 6(4), 98-116. http://hdl.handle.net/10216/118596; DOI: https://doi.org/10.24840/21830606 _006.004_0007 


\section{Introduction}

This paper is based on case studies of great innovations, and attempts at observing common patterns between them as well as significant peculiarities. Some results were reported earlier (Hök, 2017a, b), and the focus in this paper will be aspects related to utopian ideas. The focus is motivated by the observation that great innovations are associated with basic ideas highlighting the progress compared to the state of the art. These ideas may look obvious in retrospect, but when conceived by the innovators, they were more relevantly described as utopian (Hök, 2017b, pp. 29-31, 162-167).

The concept of 'great innovations' is given a wide scope, encompassing not only new products, technology, services and processes, but also other breakthroughs of high significance. Great innovations occur in many parts of society, and their processes include aspects which may be partly opposing and partly complimentary. Fig. 1 is an attempt to visualize some of these aspects. Ideas and problems are mutually complimentary, and so are, in a sense, truths and values, and discoveries and inventions. The coverage of these aspects was believed to be important in the selection of cases to visualize the many-faceted conditions under which great innovations evolve. Each one of the six innovation cases were selected to highlight one of the aspects (Hök, 2017b, p. 14).

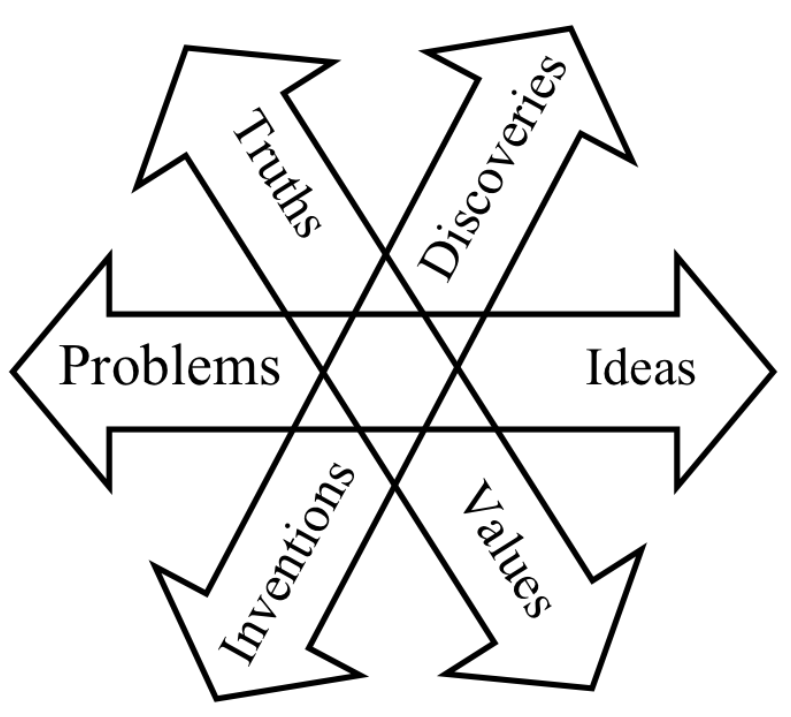

Fig. 1. Illustration of several mutually interdependent aspects of innovation.

Additional criteria for the selection of case stories were the following: They should have resulted in major impact within their fields, be well documented by independent reporters, be mutually separable, and be comprehensive to analysis outside a narrow range of expertise.

The underlying innovation idea was typically expressing the purpose, solution, or unique feature of the innovation. An idea is defined as utopian if it would have been considered either imaginative, unexpected, counterintuitive or unrealistic by most people, including experts, at the time of its conception. Obviously, an idea can be considered more or less utopian, and the attributes 
could be useful to provide an estimate. The way of expressing and communicating the ideas were examined in each case and compared between the cases.

The major research question of this paper is expressed in its title, implying sets of more specific ones. One set of questions is what roles the innovators themselves and analysts have attributed to the basic ideas, when and how clearly it was communicated, and what risks the innovators were willing to take. A second set is related to the extent that the basic idea, and its utopian potential, contributed to the overall implementation and impact. A follow-up question is whether the issues brought up in this paper are relevant in view of current literature on innovation management.

A heuristic approach has been undertaken to seek answers to the research questions. Originating from ancient Greece, heuristic reasoning was reintroduced by Polya (1945) and makes use of semiquantitative estimations, or even educated guesses, to approach a problem. Estimations based on semi-quantitative scores have long been used in experimental psychology and other fields (Likert, 1932), and sometimes with surprisingly good results compared to more sophisticated methods (Kahneman, 2011, pp. 227, 257, Åstebro, Elhedhli, 2006). The resulting rules of thumb may shed some light on hidden relationships and may even become useful, even if they do not completely meet the criteria of a scientific theory.

\section{Case studies}

The case studies, all representing great innovations, and selected from the criteria and aspects mentioned in the introduction, were the following:

- The theory of relativity is an example of a scientific theory having profound impact on our view of the world and its cosmic context. It is innovative both with respect to the scientific methods used (seeking truth), and its impact.

- The discovery of the DNA molecular structure and its consequential effects on our understanding of the hereditary mechanism of almost all biological life on earth. It represents the aspect of scientific discovery.

- The abolition of apartheid in South Africa was a unique political process lasting more than half a century and finally resulting in democracy with equal human rights regardless of ethnicity. It represents the aspect of values.

- The invention of the World Wide Web and its acceptance as the global standard for digital information storage, access, and retrieval. Inventions, patented or not, are inherent parts of most innovations with technological contents.

- The mathematical proof of Fermat's conjecture, a problem clearly articulated 358 years before it was finally solved. It represents the problem-solving aspect.

- The smartphone innovation resulting in unprecedented communicating possibilities accessible to a large part of the global human population. It represents idea-driven innovations with a commercial purpose.

In the following subsections, each one of the case studies will be shortly described with focus on their basic underlying ideas. 


\section{1 "All motion is relative"}

Everyone knows that it takes effort both to raise or to set a heavy object in motion. According to Newton's theories, the motion of physical bodies is determined by the forces of inertia and gravity. The theories work well in everyday situations but are inconsistent on the astronomic scale. Albert Einstein approached these inconsistencies by the bold assumption that inertia and gravity are manifestations of one and the same basic phenomenon. He also asserted that all motion is relative ('there is no absolute motion', Einstein, 1949, p. 41).

Rather than building on empirical data, Einstein used imaginative thought experiments in his scientific approach. His idea occurred when he realized that a person travelling through empty space cannot distinguish between acceleration and gravity. The idea had a profound impact on the further development. He managed to deduce some basic physical and mathematical consequences and started to elaborate on a theory that would describe gravitational phenomena in a complete and consistent manner.

While trusting his own ability to manage the obstacles related to theoretical physics, Einstein was less confident in the non-Euclidean mathematics which had to be managed. Therefore, he joined partnerships that eventually turned into rivalry. The race towards the goal was dramatic, but Einstein was finally able to complete the general theory of relativity eight years after the illuminating thought experiments.

Einstein's theories of relativity are knitting together space and time into a four-dimensional space-time, in which matter and energy are key elements. The theories not only resolved the Newtonian inconsistencies. They also predicted important phenomena, such as nuclear power, the 'big bang', black holes, and gravitational waves, which were experimentally verified much later.

The theories of relativity are considered one of mankind's greatest intellectual achievements (Isaacson, 2007, p. 246). This innovation radically changed our view of the world and the universe, introducing a new and more truthful description of the interrelationship between space, time, matter, and energy. It was the result of a utopian idea being highly unexpected and counterintuitive from everyday experience. The idea raised hopes towards 'a theory of everything' which would include all types of interaction also at the microcosmic scale (Greene, 1999).

\section{2 "DNA is the carrier of the genetic code"}

The transfer of genetic information from one biological generation to the next was a scientific riddle for centuries. It was not until the beginning of the $20^{\text {th }}$ century that this transfer was located to the chromosomes within biological cells. And it took some further decades to isolate, characterize and identify the active substance, deoxyribonucleic acid, or DNA for short. It was revealed that the molecule is partly built up by a comparatively rigid, threadlike sugarphosphate backbone structure combined with four smaller nucleotides, adenine, cytosine, guanine and thymine, attached to the thread. Using a combination of X-ray diffraction analysis and theoretical modelling, the three-dimensional structure of DNA was finally disclosed by a BritishAmerican research team. The DNA molecule consists of a double helix held together by weak 
hydrogen bonds between the nucleotides, like pearls on a string. Adenine on one strand always connects to thymine on the other strand, and cytosine always connects to guanine.

The sequence of nucleotide pairs between the two strands of the DNA double helix is the carrier of the genetic code. The double helix can be zipped and unzipped on chemical command, enabling the molecule and the code to be replicated. This procedure is taking place whenever biological cells divide to enable growth.

The basic idea of linking molecular structure with the hereditary mechanism was utopian in the sense that the results were completely unexpected. The link was probably implicit in the minds of the researchers, but it was only in retrospect that the idea was clearly articulated. It was definitely 'in the air' at the time, and at least one highly competent research group was working with a similar objective. This group was lagging behind in the absence of high-quality X-ray diffraction data (Watson et al, 1953, Watson, 1968).

Interestingly, the British-American project team was far from coherent. It was a mixture of specialists and generalists with different background and approach, possibly an important success factor in view of the interdisciplinary nature of the project. It started as a study of the threedimensional molecular structure and ended up in a completely new and basic understanding of the hereditary mechanism of almost all biological life on earth.

The disclosure of the DNA molecular structure started a scientific boom in genetics, pharmaceutics, nanoscience, and genetic engineering. Mapping of the genomes of several species, including the human, was performed, and the possibility of manipulating the genetic code became apparent. The processes of industrialization and commercialization are on-going.

\section{3 "Equal human rights"}

Nelson Mandela, the son of a South African tribal leader, was born into the clash between the black majority and the ruling white minority. The growing black opposition to the unjust and cruel apartheid rules were met by further suppression, denying basic human rights to the non-white population, and enforcing massive segregation. Nelson Mandela took leadership in a militant youth branch of the African National Conference (ANC), seeing no other options than armed struggle. During the 50's and 60's the situation deteriorated and almost reached the point of civil war. Mandela and several other black leaders were arrested and sentenced to life imprisonment on the charge of treason.

It looked very much like a victory to the regime, and the ANC leaders had to change strategy from their exile or imprisonment. Civil disobedience by the black citizens, and sanctions from the international community were major elements. In prison, Mandela changed his attitude from militant to respectful, but without compromising on the basic principle of equal human rights regardless of skin color. Very slowly, the apartheid regime realized that its days in power were counted. After 27 years of imprisonment, Mandela and his co-prisoners were released. It did not take more than three more years before he was elected President of South Africa, and in a position to pass legislation on the basic human rights of all people (Mandela, 1994, Sampson, 1999).

The abolition of South African apartheid was a political innovation process passing through the 
stages of awareness, acceptance and demand, in common with many other great innovations (Strassburger, 2012, Hök, 2017b, p. 32). Each stage requires its specific strategy, and a common mistake is to overestimate the recent progress. Maintaining the basic idea of equal rights - which was clearly utopian at the time - is another common element. For a political innovation to be successful in a reasonably democratic environment, it is of paramount importance to rely on ideas and values shared by most citizens. Mandela's repeated statements of equal rights - not favoring anyone - finally made an impression also on his adversaries.

The strategy of repeating again and again the message of equal rights without pointing fingers proved to be successful. In the best of worlds, this example will be a lighthouse in an otherwise dark century both to remaining tyrannies and to freedom fighters all over the world.

\section{4 "Anything being potentially connected with anything"}

The idea behind the World Wide Web can be traced back to the childhood of its inventor, Tim Berners-Lee, and a household dictionary with the suggestive title Enquire Within upon Everything. The book ignited a spark of inspiration in him which eventually evolved into his vision of the web: Anything being potentially connected with anything (Berners-Lee and Fischetti, 1999, p. 1). And connecting is exactly what the web does - with anything accessible on the internet. By 'potentially' is understood that the connection can be controlled by someone or performed automatically. The idea was certainly unexpected by most people in the year 1989, even experts. Two separate movements made it possible: Hypertext and the internet. In the modest words of the inventor, "the task left for me was to marry them together" (ibid, p. 6).

Tim Berners-Lee pursued his basic idea by deriving the necessary principles of universality, identity, equality and accessibility. Eventually, these principles were transformed into a software prototype resting on three legs: the uniform resource locator (url), the hypertext transfer protocol (http), and the hypertext markup language (html). The scalability of the concept was verified already at the prototype stage. It had to be downscaled for the lack of resources and development capacity. The upscaling is still on-going, although the web has penetrated almost all corners of society, all over the world.

The web is based on open source software and is possibly the most prominent example of an open innovation as opposed to innovations with commercial purposes. The original idea was expanded to encompass humanistic and social dimensions, while preserving a free marketplace for commercial applications. Companies like Google, Facebook, eBay, Amazon, etc., were enabled by the free web and internet infrastructure.

Together with the internet, the World Wide Web is possibly the most important innovation of our time. Its total impact can hardly be overestimated. Already in 2010, its contribution to the economy of developed countries amounted to 3-8\% of their GDP (https://www.statista.com/ chart/185/the-economic-contribution-of-the-world-wide-web/), and is rapidly growing. According to current statistics (http://www. internetlivestats.com/total-number-of-websites/), there were approximately 1.8 billion websites in March 2018, and the number is growing exponentially with a growth rate of doubling every second year, very much in line with Moore's 
'law' regarding the rate of performance improvement of microelectronic devices (Moore, 1965, Kurzweil, 2006).

The importance of the basic, utopian idea as a success factor is undisputable. First, it provided a software platform beyond the commercial interests of the rapidly growing marketplace of data communication. Second, the rapid initial growth was enabled by the free access to the software tools. Third, the generous conditions and transparency promoted the growth of new applications, products and services relying on the web.

\section{5 "Fermat's statement was correct"}

The French lawyer and amateur mathematician Pierre de Fermat (1601-1665) brought generations of mathematicians into a state of perplexity by his provocative statement that the simple equation

$$
a^{n}+b^{n}=c^{n}
$$

has no whole number solutions when $\mathrm{n}$ is greater than 2. Fermat indicated he could prove his statement but only a proof for the special case of $n=4$ was found among his legacies. The utopian character of the statement becomes obvious by the fact that it took 358 years to resolve it. The riddle became well-known far outside the professional circles, and everyone wondered whether the statement was correct or not, or if the problem was simply unsolvable. In 1994, the British mathematician Andrew Wiles finally proved that Fermat's statement had been correct. His proof involved complex mathematics completely unknown at Fermat's time. It was a proof of induction involving modular forms and elliptic equations (Wiles, 1995).

Andrew Wiles was only ten years old when he first heard of Fermat's riddle. His childhood dream grew to an obsession when he realized that he may be in a unique position to resolve it. The utopian character of the challenge certainly must have contributed to his creative decisiveness and endurance.

Wiles described the problem-solving process as entering one dark room after another, and experiencing occasional flashes of light, only to be extinguished by setbacks. To the question how he could spend eight years pondering about this problem, Wiles answered that he just loved to work on it, and pitting his wits against it (Singh, 1997, p. 253). Most of the time he chose to work in solitude only broken on rare occasions which, however, had a profound impact on the outcome due to influences from colleagues (Singh, 1997, Stewart, 2013).

Solutions to great mathematical problems are innovations in several respects. They expand the knowledge horizon, represent significant intellectual progress, and they introduce new concepts and strategies which may become useful in another context (Ellenberg, 2014).

A remaining enigma is how and why Pierre de Fermat had the audacity to make his statement. It will probably remain unknown whether it was mathematical intuition, plain mockery, or something else.

\section{6 "A universal communication tool for all"}

During the first years of the new millennium, cellphone suppliers competed against each other 
on three main aspects: size, coverage and battery-life. There certainly existed ideas to take the market out of this chicken race, but only one outsider, Apple, had the audacity, competence and resources to bring the issue to its head, and to pursue its basic idea of a universal communication tool for all.

The launching of the iPhone in 2007 disrupted the cellphone market by introducing a new and flexible user interface based on a multi-touch screen. The screen could be used as a keyboard or as an interactive display of almost anything. Easy internet access, roaming, streaming of music, photography, and many other functions besides phoning and messaging was enabled with innovative software. The introduction in 2008 of the AppStore, a new arena for applicationoriented software, further defined a demarcation line of the smartphone innovation (Isaacson, 2011, Merchant, 2016).

The smartphone innovation coincided with the breakthrough of social media, and other internet services. The smartphone is more used for surfing than for talking. Typically. the time of use per day has increased dramatically from minutes to hours. And the number of smartphone users worldwide are counted in billions.

It took more than two years for the main competitors to catch up with Apple, and some major suppliers of cellphones never recovered from the disruption. A decade after their introduction, another chicken race with less margins seems to be striking the smartphone business. The product has now become a commodity.

In retrospect, it seems that the timing of the basic idea of a versatile communication tool was close to optimal. Apple enjoyed a couple of years without competition and used it very efficiently to build a strong market position. The idea was utopian in the sense that it was against all odds, and it was clearly communicated to the market. It had a huge economic impact.

\section{Results}

In this section, the results of a combined analysis of the case studies will be reported. More specifically, the two sets of questions mentioned in the introduction will be addressed. In the first subsection the roles and importance of the basic ideas will be analyzed and compared between the different case studies. The second and third subsections deal with the utopian potential of the ideas and how it relates to the total innovation impact. These subsections thus relate to the second set of questions.

\subsection{Roles, importance and risks of the basic ideas}

In this subsection, the results of analysis will be summarized concerning the roles of the basic ideas. Typically, the essence of the ideas could be expressed in a short sentence comprehensive to most educated people. All the basic ideas fulfilled at least one of the utopian criteria of being considered imaginative, unexpected, counterintuitive or unrealistic.

The analysis aimed at defining a major role for each case, and the results are summarized below.

Einstein repeatedly referred to his revelation of inertia and gravity as being manifestations of one 
single origin as his 'happiest thought' which was guiding him through the hurdles of theoretical development. The expression 'there is no absolute motion' was a direct consequence and enabled the conception of a basic principle and set the boundary conditions for the general theory of relativity.

The idea of using the DNA molecular structure as a means for disclosing the underlying, hereditary mechanism was understood but not clearly articulated by the research team. Still it served as motivation to carry on their research efforts.

Through the decades of struggle to abolish apartheid, Nelson Mandela changed strategy and tactics several times but remained faithful to the basic idea of equal human rights. Ultimately, the opposite idea was not defendable, and finally, the ruling white minority found themselves at the pillory with no way out other than trusting the mercy of the new, democratically elected majority rulership. Intentionally or not, the idea of equal rights became a political 'bat'.

The universality of the basic idea behind the World Wide Web and its conceptual underpinnings are as crucial today as they were in the early development phase. The use and abuse of the web need to be constantly monitored and balanced. The openness is sharply contrasting to powerful commercial interests. The basic idea was truly visionary.

Andrew Wiles expressed his strong commitment to solving the Fermat enigma on emotional grounds and it evolved as a personal target (Singh, 1997). He shared the idea with hundreds of skillful mathematicians before him, but he was convinced that he had a unique chance to realize it.

The commitment of the Apple team, including the founder and CEO, Steve Jobs, to the basic idea of the smartphone innovation is beyond doubt (Isaacson, 2011). The previous innovations, starting with the Macintosh personal computer, was an early revolution of user-friendliness, and the multitouch screen combined with advanced software solutions of the iPhone enabled a truly intuitive, simple and versatile user interface. The idea of a universal communicating tool for all was a commercial objective receiving the unanimous focus of the extremely competent Apple development team.

In table 1, the roles, importance and risks associated with the basic ideas in each of the innovation cases are summarized. In four out of six cases the basic ideas were formulated by the innovators themselves according to the biographies (Einstein, 1949, Mandela, 1994, and Berners-Lee and Fischetti, 1999, Isaacson, 2011). The basic ideas of the remaining two cases were concluded from literature (Watson, 1968, Singh, 1997).

The importance of the basic ideas in the eyes of the innovators themselves and by analysts were estimated by ranking the individual cases based on analysis of the available documentation. The basic idea of the World Wide Web is topping the ranking (six) of idea importance, followed by the smartphone innovation (five). In both these cases, the uniqueness of the idea was crucial for the subsequent development. Almost equal importance was attributed to the relativistic idea (four) followed by that of equal human rights (three) which ultimately became irresistible. The motivation provided by the idea behind the DNA structure disclosure (two) was considered less important, and so was the Fermat idea (one), having been formulated three centuries earlier. 
Innovative projects are high-risk ventures, both from a personal and a management perspective. There was a wide variation with respect to risk exposure between the analyzed innovations. Nelson Mandela and several other ANC leaders faced the possibility of being sentenced to death for the accusation of treason. Among the selected cases, they are topping the risk ranking list (six). The smart phones venture was less dramatic (five), but the entire company was at stake from the high commercial risk operation. Further down the risk list comes the World Wide Web (four), Fermat's conjecture (three), and relativity theory (two). The DNA team basically took no risks at all (one).

Table 1. The major roles, importance and risks of the basic ideas in each one of the innovation cases.

\begin{tabular}{lllcc}
\hline \multicolumn{1}{c}{ Innovation } & \multicolumn{1}{c}{ Basic idea } & Major role & $\begin{array}{c}\text { Idea } \\
\text { importance } \\
\text { ranking 6:1 }\end{array}$ & $\begin{array}{c}\text { Risk } \\
\text { ranking 6:1 }\end{array}$ \\
\hline Relativity theory & All motion is relative & $\begin{array}{l}\text { Underlying } \\
\text { principle }\end{array}$ & 4 & 2 \\
\hline $\begin{array}{l}\text { Disclosure of the } \\
\text { DNA structure }\end{array}$ & $\begin{array}{l}\text { DNA is the carrier of the } \\
\text { genetic code }\end{array}$ & Motivation & 2 & 1 \\
\hline $\begin{array}{l}\text { Apartheid } \\
\text { abolition }\end{array}$ & Equal human rights & Political 'bat' & 3 & 6 \\
\hline World Wide Web & $\begin{array}{l}\text { Anything being potentially } \\
\text { connected to anything }\end{array}$ & Vision & 6 & 3 \\
\hline $\begin{array}{l}\text { Fermat's } \\
\text { conjecture }\end{array}$ & $\begin{array}{l}\text { Fermat's statement was } \\
\text { correct }\end{array}$ & Target & 1 & 5 \\
\hline Smartphones & $\begin{array}{l}\text { A universal } \\
\text { communication tool for all }\end{array}$ & Objective & 5 & 4 \\
\hline
\end{tabular}

\subsection{Overall impact and utopian idea potential}

In this subsection, the overall impact and the utopian idea potential will be investigated. As in the previous subsection, ranking between the innovation cases was chosen to allow semi-quantitative comparison. Ranking was based on adding the scores of subordinate variables.

Table 2 shows the results of ranking the innovations with respect to overall impact. For guidance each of the innovations were assigned a score of low (1), medium (2) and high (3) with respect to the variables of economy, knowledge and society. Then the overall impact score and ranking were obtained from the score sum.

The www innovation was the only one to score high in all three variables. The Fermat solution scored low in their economical and societal impact, and medium with respect to knowledge. Therefore, positioning these innovations at the top six and bottom one of the ranking scale was obvious. The impact of the smartphone innovation was ranked as five, scoring high on both economical and societal impact. The abolition of apartheid, the theory of relativity, and the DNA structure discovery were ranked in the declining scale as four, three, and two. 
Table 2. The six innovation cases are ranked with respect to their overall impact (right column), and their score with respect to economy, knowledge, and society as input ( $\mathrm{H}=$ high, $\mathrm{M}=$ moderate, $\mathrm{L}=$ low) appearing at the columns in between.

\begin{tabular}{lccccc}
\hline Innovation & Economy & Knowledge & Society & $\begin{array}{c}\text { Impact } \\
\text { score 9:3 }\end{array}$ & $\begin{array}{c}\text { Impact } \\
\text { ranking } \\
\text { 6:1 }\end{array}$ \\
\hline Relativity & $\mathrm{L}$ & $\mathrm{H}$ & $\mathrm{M}$ & 6 & 3 \\
\hline DNA & $\mathrm{L}$ & $\mathrm{H}$ & $\mathrm{L}$ & 5 & 2 \\
\hline Apartheid abolition & $\mathrm{H}$ & $\mathrm{M}$ & $\mathrm{H}$ & 7 & 4 \\
\hline WWW & $\mathrm{H}$ & $\mathrm{H}$ & $\mathrm{H}$ & 9 & 6 \\
\hline Fermat & $\mathrm{L}$ & $\mathrm{M}$ & $\mathrm{L}$ & 4 & 1 \\
\hline Smartphones & $\mathrm{H}$ & $\mathrm{M}$ & $\mathrm{H}$ & 8 & 5 \\
\hline
\end{tabular}

The utopian potential of an idea is defined as the combined effect of its imaginative, unexpected, counter-intuitive and unrealistic attributes. Fig. 2 illustrates the fact that the variables are different but mutually interdependent. Highly innovative ideas typically include more than one of them. The utopian 'hub' of an idea corresponds to the intersection area, whereas its 'range' corresponds to the total area. A semi-quantitative approach was adopted to provide a ranking of the utopian potential from the sum of scores of the individual variables on a relative scale.

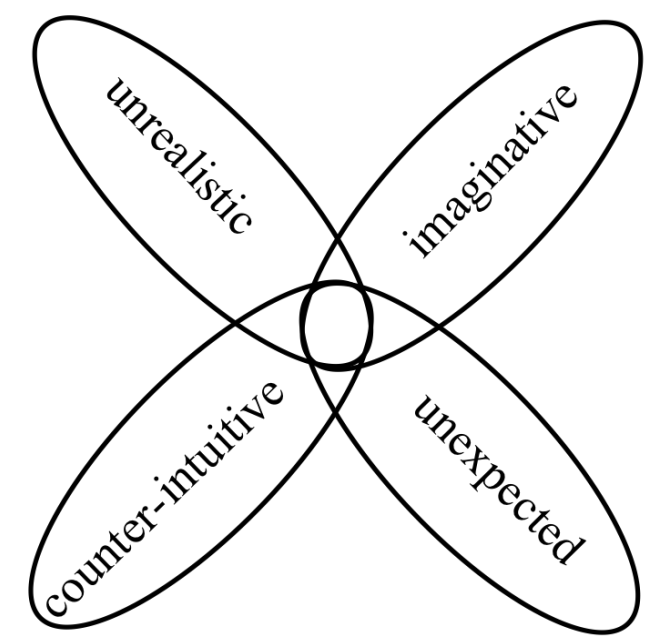

Fig. 2. Utopian ideas include imaginative, unexpected, counter-intuitive and unrealistic attributes.

In Table 3, the six innovation cases are ranked with respect to the utopian potential of their basic ideas. The imaginative, unexpected, counter-intuitive, and unrealistic appearance of the ideas was used to score them according to an assignment of 'high' (3), 'moderate' (2), or 'low' (1). The added scores were then used for ranking the ideas between the innovation cases. The added scores and ranking are the columns at right of Table 3. Quotation marks were used for 
the score variables in Table 3 to underline their subjective nature. The scores were estimated from the general understanding and attitudes at the time of idea conception.

As shown in Table 3, the score of the idea behind the World Wide Web innovation was high in all variables, whereas the corresponding Fermat scores were low in all aspects except the variable of unrealism. It should be noted that the Fermat ranking is based on the starting situation for the main innovator, Andrew Wiles. Consequently, the www and Fermat innovations were ranked as top (six) and bottom (one), respectively. Relativity scored high, high, high, moderate, resulting in rank five. Smart phones, apartheid abolition, and the DNA structure innovation with intermediate scores ranked as four, three and two, respectively. The distinction between the variables is illustrated by the fact that none of the columns had identical scores.

Table 3. The six innovation cases are ranked with respect to the utopian potential of their basic ideas based on whether they were considered imaginative, unexpected, counter-intuitive and unrealistic at the time of conception using the scale of $\mathrm{H}=$ high, $\mathrm{M}=$ moderate, $\mathrm{L}=$ low.

\begin{tabular}{lcccccc}
\hline Innovation & $\begin{array}{c}\text { "Imagi- } \\
\text { native" }\end{array}$ & $\begin{array}{c}\text { "Un- } \\
\text { expected" }\end{array}$ & $\begin{array}{c}\text { "Counter- } \\
\text { intuitive" }\end{array}$ & $\begin{array}{c}\text { "Un- } \\
\text { realistic" }\end{array}$ & $\begin{array}{c}\text { Utopian } \\
\text { potential } \\
\text { score } \\
\mathbf{1 2 : 4}\end{array}$ & $\begin{array}{c}\text { Utopian } \\
\text { potential } \\
\text { ranking } \\
\mathbf{6 : 1}\end{array}$ \\
\hline Relativity & $\mathrm{H}$ & $\mathrm{H}$ & $\mathrm{H}$ & $\mathrm{M}$ & 11 & 5 \\
\hline DNA structure & $\mathrm{L}$ & $\mathrm{H}$ & $\mathrm{L}$ & $\mathrm{M}$ & 7 & 2 \\
\hline Apartheid abolition & $\mathrm{M}$ & $\mathrm{M}$ & $\mathrm{M}$ & $\mathrm{H}$ & 9 & 3 \\
\hline World Wide Web & $\mathrm{H}$ & $\mathrm{H}$ & $\mathrm{H}$ & $\mathrm{H}$ & 12 & 6 \\
\hline Fermat's conjecture & $\mathrm{L}$ & $\mathrm{L}$ & $\mathrm{L}$ & $\mathrm{H}$ & 6 & 1 \\
\hline Smart phones & $\mathrm{H}$ & $\mathrm{H}$ & $\mathrm{M}$ & $\mathrm{M}$ & 10 & 4 \\
\hline
\end{tabular}

\subsection{Covariation of idea importance, risk, utopian potential and overall im- pact.}

In this subsection, the results of ranking in various respects between the case studies presented in the previous subsections will be presented in graphs indicating the presence or absence of covariation.

In Fig. 3 the ranking of the overall personal risk induced to the innovators is indicated as a function of the ranking of idea importance from Table 1. The positions are widely spread with two ('equal rights', 'Fermat') above the identity line, and three ('www', 'relativity', 'DNA') below it. Only the 'smartphones' were equally ranked with respect to risk and idea importance. There seems to be no clear indication of correlation between idea importance' and risk exposure.

Different criteria were used for the ranking of idea importance and utopian potential as described in sections 3.1 and 3.2. When the ranking of utopian idea potential is plotted against the ranking of idea importance in Fig. 4, four positions ('www', 'equal rights', 'DNA', and 'Fermat') coincide 


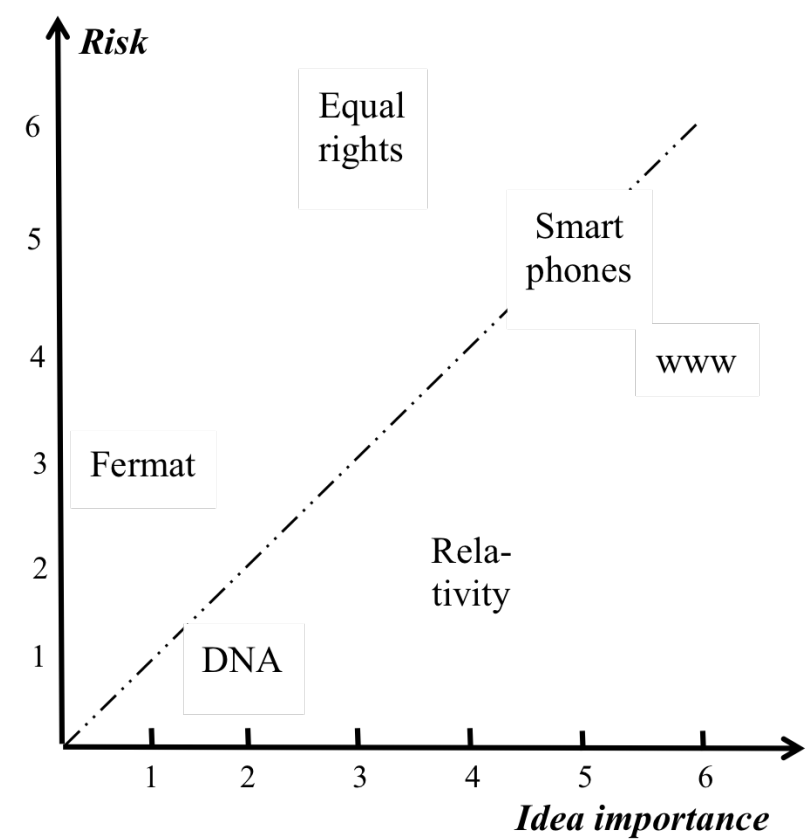

Fig. 3. The graph shows the overall risk ranking as a function of the idea importance ranking according to data of Table 1.

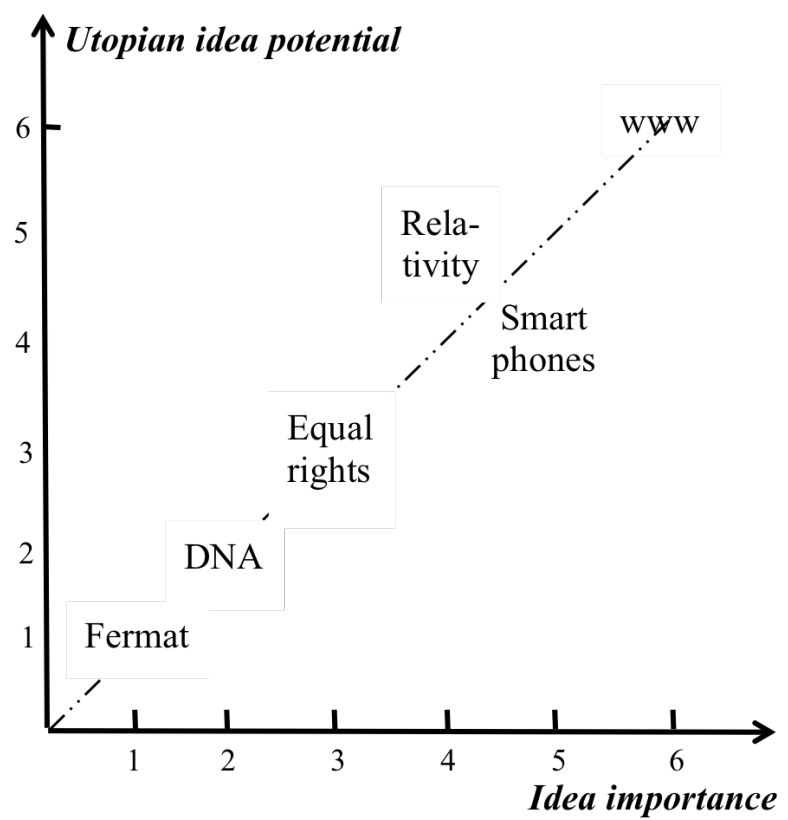

Fig. 4. The graph shows the utopian potential ranking as a function of idea importance ranking with data from Tables 1 and 3 . 


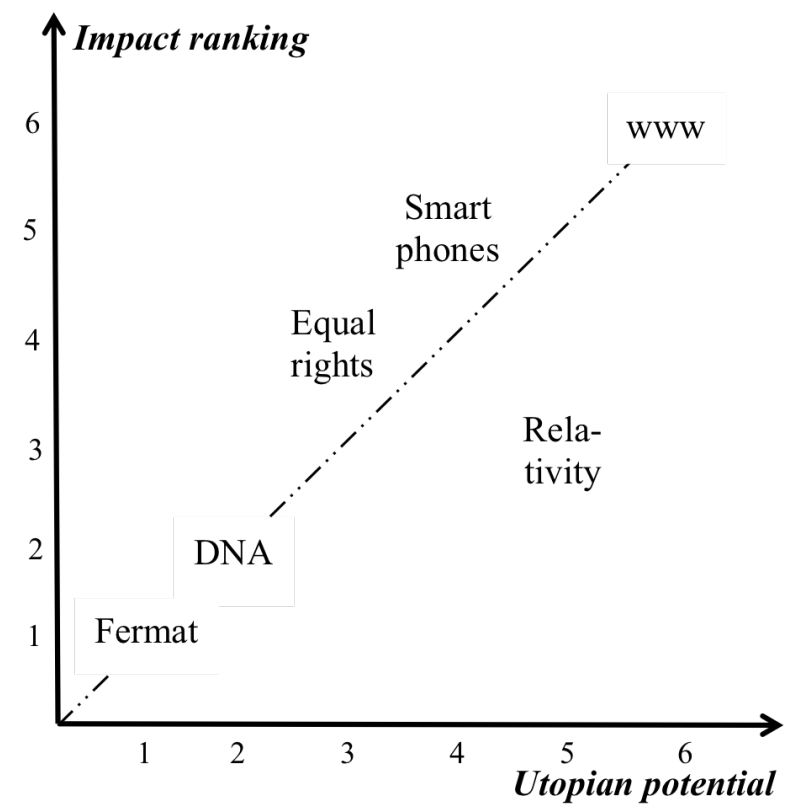

Fig. 5. The graph shows the total impact ranking as a function of the utopian potential ranking (data as in Tables 2 and 3).

with the identity line. The smartphone idea was considered somewhat more important than utopian as compared to the relativity idea.

The rankings of overall impact and utopian idea potential of tables 2 and 3 were brought together in the graph of Fig. 5, with the ranking of utopian idea potential as abscissa, and the ranking of overall impact as ordinate. In three cases ('www', 'DNA', and 'Fermat') the rankings were identical. The utopian idea ranking of the 'relativity' case deviated from the identity line by +2 units, whereas the corresponding deviations for the 'smartphone's and 'equal rights' cases were -1 in both cases. The graph suggests that the two rankings are correlated.

\section{Discussion}

From subsection 3.1, it is concluded that the roles of the basic ideas were quite different in the different innovation cases. In the Mandela case the idea evolved to become a political 'bat', whereas the DNA idea was reduced to a much vaguer role of motivation. The ideas of Einstein and Berners-Lee had a visionary significance, whereas the ideas behind the Fermat and smartphone cases served as target or objective. The large variation suggests that their importance also varied considerably. But the four biographies (Einstein, 1949, Mandela, 1994, Berners-Lee and Fischetti, 1999, and Isaacson, 2011) in which the respective basic ideas were specifically described, provide support for their importance in these cases. The personal risks taken by the innovators varied from none to a life-threatening situation. This variation was due to external political or economic circumstances rather anything else.

From sections 3.1 and 3.2 it is concluded that all the basic ideas of the case studies can be considered utopian according to the definition in the introduction. The rankings of overall impact and 
utopian potential were each based on the estimated score in three and four variables, respectively. The impact ranking seemed quite straight-forward, whereas the ranking of utopian potential depended on estimated variable scores based on interpretations of the available documents and was therefore more subjective.

The graphs of Figs. 3, 4, and 5 in subsection 3.3 indicate the covariation between the rankings of idea importance, risk, utopian potential and impact. According to Fig 3, the correlation between idea importance and risk is weak as expected if risk should largely be depending on external circumstances. Perhaps not surprisingly, the utopian potential and idea importance seem to be highly correlated (Fig. 4), even though the criteria are somewhat different. Most important, however, is the correlation between utopian idea potential and overall impact (Fig. 5). A possible explanation is that self-fulfillment of great and utopian challenges may result from positive feedback from partners, sponsors and supporters ( $\mathrm{cf}$ 'the innovator's paradox - the chance of success may increase with the magnitude of the challenge', Hök, 2017b, p. 162). This finding is considered a significant result of the present investigation.

The definitions of 'impact', 'utopian', etc. were derived from common language use of these terms and variables without extensive linguistic or semantic analysis. It seemed reasonable as a first approach in view of the present research questions. The rankings based on the scores of each individual variable enabled semi-quantitative comparisons to be performed as shown in Figs. 3, 4 and 5. However, there is room for further research and development.

Are great innovations driven by utopian ideas? The present investigation does not provide a straight answer to this question. On the one hand, the correlation between utopian potential and impact provides support of the main hypothesis. It could also be argued that one, or a few of the innovation cases, e. g. the World Wide Web and smartphone innovations, constitute proofof-existence for great innovations driven by utopian ideas. On the other hand, this investigation does not exclude the existence of great innovations not driven by utopian ideas. The statement therefore remains to be hypothetical until more evidence have been accumulated.

The use of a semi-quantitative method is motivated by its power to bring the major research question and its related follow-up questions to a head. It will be possible, however, to extend and improve the present investigation by (i) further elaborating the concept of utopian potential and other key concepts into more quantifiable entities, (ii) using the combined response from a qualified test panel to increase objectivity, and (iii) significantly increasing the number of innovation categories and cases. An extended investigation could also address other related aspects of risk management, funding, consequence analysis, commercialization strategies (Walsh, 2012), third-party involvement, etc.

The implications from a managerial/policy perspective could become significant after implementation of an extended investigation as outlined above. A standardized algorithm to determine the utopian potential would enable self-assessment to be used by innovators, or as a screening tool for analysts and investors. Of course, innovators also need to convince themselves, partners, investors, suppliers, customers, and ultimately users, that despite its high utopian potential, their idea is in fact realizable (Author 2017b, pp. 29-31).

In contrast to the findings of this investigation, current literature on innovation management tends to depreciate the importance of basic ideas. According to Govindarajan and Trimble 
(2005, p. 185f), "in all great innovation stories, the great idea is only Chapter 1". "Forgetting, borrowing and learning" in an iterative and adaptive process is more important in the innovation model proposed by these authors.

The disruptive innovation model of Christensen and Raynor (2003, p. 44f) is based either on lowend disruption addressing overserved customers with a lower-cost business model or new-market disruption competing against non-consumption. The disruptive model has been criticized for the prevalence of both false positives and false negatives (Lepore, 2014), however with no suggestions to improve it. The role of basic ideas is left unnoticed. Some analysts even seem to doubt that predictable innovation models are possible (Kahneman, 2011, pp. 204-208, 218-221).

The understanding of innovation processes is still fragmentary, and there is a wide divergence between different teachings (Hök, 2017b, pp. 151-158). The results of the present investigation could hopefully stimulate to more research in the area.

\section{Acknowledgements}

The encouragement of Mobyen Uddin Ahmed, Gunnar Bark, Mats Björkman, Andras Gedeon, Raimo Gester, Arne Gustafsson, Olof Jusinski, Mark Hawthorne, Peter Lageson, Maria Lindén, Jonas Ljungblad, Göran Lundin, Hans Martin, Håkan Pettersson, Christer Svensson, Robert Strassburger, Lasse Tenerz, Masato Terada, Johan Wiklander, Michael Willis, Bud Zaouk and Martin Åhlenius for this work is highly appreciated. 


\section{References}

Berners-Lee, T., Fischetti, M. (1999). Weaving the web. The original design and ultimate destiny of the World Wide Web. Harper Collins, New York, 1999.

Christensen, C. (1997). The innovator's dilemma, Harvard Business School Press, Boston, 1997.

Christensen, C., Raynor, M. (2003). The innovator's solution, Harvard Business School Press, Boston, 2003.

Einstein, A. (1949). The theory of relativity, Chapter 10 in Out of my later years, Philosophical Library, New York, 1956.

Ellenberg, J. (2014). How not to be wrong - the power of mathematical thinking, Penguin Books, New York, 2014.

Govindarajan, V., Trimble, C. (2005). Ten rules for strategic innovators, Harvard Business School Press, Boston, 2005.

Greene, B. (1999). The elegant universe. Superstrings, hidden dimensions, and the quest for the ultimate theory, Vintage, London, 1999.

Hök, B., Stubbe, R., Tenerz, L. (2011). Inside innovation - hur man får det att hända, Bookhouse Publishing, Stockholm, 2011.

Hök, B., (2017a). A heuristic approach to innovative problem solving, Int. J. Engineering Research and Applications, IJERA, Vol. 7, Issue 2, Feb. 2017, pp. 72-77.

Hök, B., (2017b). Logic \& Magic. The double nature of innovation. Books on Demand, Stockholm, Sweden, 2017.

Isaacson, W. (2007). Einstein: His life and universe. Simon \& Schuster, New York, 2007.

Kahneman, D. (2011). Thinking, fast and slow, Farrar, Straus and Giroux, New York, 2011.

Kurzweil, R. (2005). The singularity is near. When humans transcend biology. Viking Penguin, New York, 2005.

Lepore, J. (2014). The disruption machine - what the gospel of innovation gets wrong, The New Yorker, June 23, 2014. 
Likert, R. (1932). "A technique for the measurement of attitudes". Archives of Psychology. 140, $1-55$.

Mandela, N. (1994). Long walk to freedom, Little, Brown, London, 1994.

Moore, G. E. (1965). Cramming more components onto integrated circuits, Electronics, pp. 114-117, April 19, 1965.

Pólya, G. How to solve it, Princeton University Press, New York, 1945.

Sampson, A. (1999). Mandela. The authorized biography, Vintage, 1999.

Singh, S. (1997). Fermat's last theorem. The story of a riddle that confounded the world's greatest minds for 358 years. Fourth Estate, London, 1997.

Stewart, I. (2013). Great mathematical problems. Marvels and mysteries of mathematics. Profile Books, London, 2013.

Strassburger, R. (2012). Private communication.

Walsh, P. R. (2012). Innovation Nirvana or Innovation Wasteland? Identifying commercialization strategies for small and medium renewable energy enterprise. Technovation, vol 32, Issue 1, 3242 .

Watson, J. D., Crick, F. H. C. (1953) Molecular structure of nucleic acids: A structure for deoxyribose nucleic acid, Nature, No. 4356, April 25, 1953.

Watson, J. D. (1968) The double helix. A personal account of the discovery of the structure of DNA, Weidenfeld \& Nicolson, London, 1968.

Wiles, A. (1995). Modular elliptic curves and Fermat's last theorem. Annals of Mathematics, Second Series, Vol 1, No. 3, (May 1995), 443-551.

Åstebro, T., Elhedhli, S. (2006). The effectiveness of simple decision heuristics: Forecasting commercial success for early-stage ventures. Management Science 52, 395-409. 


\section{Biographies}

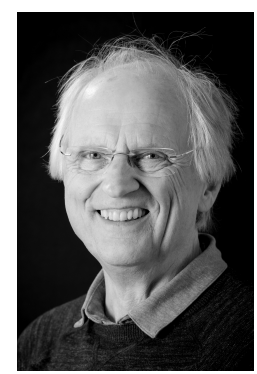

Bertil W. Hök. Bertil Hök was born in Molkom, Sweden, in 1947. The author received his M.Sc. and Ph.D. degrees from Uppsala University, Sweden, in 1970, and 1975, respectively, in electronics with specialization in microsensor systems. After employment at Siemens and ABB he founded the company Hök Instrument AB in 1986 and was its CEO until 2012. In 2017, the company was acquired by Senseair AB and now belongs to the Japanese company group Asahi Kasei. He is currently active as Senior Advisor within the company. He was an adjunct professor at Uppsala University 1984-2002, and at Mälardalen University, Västerås, Sweden, 1999-2005, and from 2016 onwards. His scientific authorship includes more than a hundred peer-reviewed papers, and he is inventor/coinventor of more than a hundred patent families. His most recent book Logic ES Magic - the Double Nature of Innovation was published in 2017. Professor Hök has received Erna Ebeling's Prize for outstanding achievements in biomedical engineering and has been awarded with SKANDIA Innovation Cup, and the SKAPA Innovation Award. He is a Fellow the Royal Swedish Academy of Engineering Sciences (IVA). 